\title{
Postoperative mortality among surgical patients with COVID-19: a systematic review and meta-analysis
}

\author{
Semagn Mekonnen Abate ${ }^{1 *}$ (D) Bahiru Mantefardo ${ }^{2}$ and Bivash Basu ${ }^{3}$
}

\begin{abstract}
Background: The coronavirus disease 2019 (COVID-19) pandemic puts perioperative providers and staff at risk of viral exposure to severe acute respiratory syndrome coronavirus-2 (SARS-CoV-2) during aerosol-generating procedures, particularly in asymptomatic carriers. However, the perioperative risk for adverse outcomes in SARS-CoV2 infected patients remain uncertain and the topic of debate. The current study was designed to determine the postoperative mortality in COVID-19 patients based on a systematic review and meta-analysis of the global published peer-reviewed literature.

Methods: A comprehensive search was conducted in PubMed/Medline; Science direct and LILACS from December 29, 2019, to August15, 2020, without language restriction. All observational studies reporting the prevalence of mortality were included while case reports and reviews were excluded. The data from each study were extracted with two independent authors with a customized format excel sheet and the disagreements were resolved by the third author. The methodological quality of included studies was evaluated using a standardized critical appraisal Tool adapted from the Joanna Briggs Institute.
\end{abstract}

Results: A total of 715 articles were identified from different databases and 45 articles were selected for evaluation after the successive screening. Twenty-three articles with 2947 participants were included. The meta-analysis revealed a very high global rate of postoperative mortality among COVID-19 patients of 20\% (95\% Cl: 15 to 26) and a postoperative ICU admission rate of $15 \%$ (95\% confidence interval (Cl):10 to 21).

Conclusion: The unexpected high postoperative mortality rate in SARS-CoV-2 infected patients of 20\% in the global literature mandates further scrutiny in assuring appropriate surgical indications and perioperative surgical safety measures in this vulnerable cohort of patients.

Registration: This systematic review and meta-analysis was registered in Prospero's international prospective register of systematic reviews (CRD42020203362) on August 10, 2020.

Keywords: Perioperative, Mortality, Prevalence, Surgery, COVID-19

\footnotetext{
*Correspondence: semmek17@gmail.com

'Department of Anesthesiology, College of Health Sciences and Medicine, Dilla University, PO.BOX:419, Dilla, Ethiopia

Full list of author information is available at the end of the article
}

(c) The Author(s). 2020 Open Access This article is licensed under a Creative Commons Attribution 4.0 International License, which permits use, sharing, adaptation, distribution and reproduction in any medium or format, as long as you give appropriate credit to the original author(s) and the source, provide a link to the Creative Commons licence, and indicate if changes were made. The images or other third party material in this article are included in the article's Creative Commons licence, unless indicated otherwise in a credit line to the material. If material is not included in the article's Creative Commons licence and your intended use is not permitted by statutory regulation or exceeds the permitted use, you will need to obtain permission directly from the copyright holder. To view a copy of this licence, visit http://creativecommons.org/licenses/by/4.0/ The Creative Commons Public Domain Dedication waiver (http://creativecommons.org/publicdomain/zero/1.0/) applies to the data made available in this article, unless otherwise stated in a credit line to the data. 


\section{Background}

The severe acute respiratory syndrome virus-2 (SARS$\mathrm{CoV}-2)$ virus that causes coronavirus disease 2019 (COVID-19) was identified in Wuhan, Hubei province of China in December 2019 by the Chinese Center for Disease and Prevention from the throat swab of a patient [1]. The Coronavirus infection mainly affects the respiratory system and is presented with fever, dry cough, and difficulty of breathing, and lately, the patient may deteriorate associated with pneumonia and acute respiratory distress syndrome [1-4] despite recent evidence on the clinical manifestation of the gastrointestinal tract, cardiac, dermatologic, cardiac and central nervous system [5-12].

World Health Organization (WHO) situational report revealed that there were more than 20 million laboratory-confirmed cases and 700 thousand deaths globally as of August13, 2020 [13]. The American region accounted for the highest number of cases and deaths which was 10 million and 400 thousand respectively [13]. The European region accounted for the secondhighest confirmed cases and death which were more than 3 million confirmed cases and 200 thousand deaths. Though the COVID-19 pandemic has emerged in the Western Pacific region, China, Hwan city, the number of infected cases, and deaths was the lowest as compared to the American and European regions [13]. The number of laboratory-confirmed cases and deaths in the African region was the lowest for the last couple of months but the rate of spreading in this region is increasing at an alarming rate and expected to be very high in the next couple of months if it continues as this rate [13-15].

The last couple of months' reports in Ethiopia were very low but there were many cases in short periods which is approximately 1000 cases and 10 deaths per day. It is estimated that the number even may be very high because the diagnosis is limited only in big cities. The huge discrepancies among counties on number of infected case and mortality may be related with testing capacity and some countries fail to report the actual data consistently due to different reasons.

The challenge of COVID-19 is very high globally due to a lack of proven treatment and the complexity of its transmission [16-20]. However, the impact is more catastrophic for low and middle-income countries because of very poor health care system, high illiteracy and low awareness of the disease and its prevention, lack of skilled health personnel, scarce Intensive Care Unit, a limited number of mechanical ventilators, and prevalence of co-morbidities/infection along with malnutrition [15, 20-22].

Epidemiological studies showed that patients with comorbidities including (Asthma, COPD, Tuberculosis, Pneumonia, Acute respiratory distress syndrome
(ARDS), Diabetes mellitus, hypertension, renal disease, hepatic disease, and cardiac disease), history of smoking, and history of substance use, male gender and age greater than 60 years were more likely to die or develop undesirable outcomes [23-26].

The outcomes of patients with coronavirus infection undergoing surgery are very variable. Studies revealed that in-hospital mortality of patients with COVID-19 was very high which varied from $152 \%$ of the hospitalized patient $[27,28]$.

Body of evidence showed that patients visiting the health institution during the COVID-19 pandemic decrease significantly despite requiring medical care which affects significantly the non-COVID-19 patients' hospital admission [29-33].

The COVID-19 pandemic imposes a significant challenge on health care delivery along with economic, social, and mental health crisis [15-18, 30, 33-42].

Surgery during the COVID-19 outbreak is challenging to the patient, health care workers, and non-COVID-19 patients [34, 35, 38, 43-46] particularly for low and middle-income countries where the limping health care systems were broken with low testing capacity, suboptimal postoperative care, lack of anesthesia machine filters and limited personal protective equipment [47-50].

Evidence revealed that mortality of patients hospitalized with COVID-19 was very high which is strongly associated with the presence of comorbidities, smoking, and substance use $[23,25,34,39,45,51,52]$.

Some studies showed that perioperative mortality of patients with COVID-19 was very high [30, 32, 45, 53-55] while some studies failed to identify significant mortality among patients with COVID-19 undergoing surgical procedures $[28,52,56,57]$.

Investigating the global prevalence and determinants of perioperative outcomes among patients with COVID19 undergoing a surgical procedure is very important to reduce patient mortality and morbidity through varies strategies including but not limited to the provision of alternative non-surgical intervention for a moderate and severe case, increasing the number of ICU beds, mechanical ventilator, skilled professionals, and integrated monitors and reducing possible risk factors. Therefore, this systematic review and meta-analysis aimed to provide global evidence on the prevalence and determinants of perioperative outcomes among patients with COVID19 undergoing surgical procedures.

\section{Methods}

\section{Protocol and registration}

The systematic review and meta-analysis were conducted based on the Preferred Reporting Items for Systematic and meta-analysis (PRISMA) protocols [58]. This systematic review and meta-analysis were registered 
in Prospero's international prospective register of systematic reviews (CRD42020203362) on August 10, 2020.

\section{Eligibility criteria}

All observational (case series, cross-sectional, cohort, and case-control) studies reporting the prevalence of mortality and its determinants among surgical patients with coronavirus disease (COVID-19) were included while studies that didn't report the prevalence of mortality among surgical patients with COVID-19, articles that didn't report full information for data extraction, articles with different outcomes of interest, studies with a methodological score less than $50 \%$, studies with randomized controlled trials, and Systemic review study design were excluded. The primary outcomes of interest were the global prevalence of postoperative mortality and the rate of postoperative ICU admission among patients with COVID-19 worldwide. The prevalence of comorbidities, prevalence of postoperative complications and lengths of hospital stay were secondary outcomes.

\section{Search strategy}

The search strategy was conducted to explore all available published and unpublished studies among surgical COVID-19 patients admitted to the hospital from December 2019 to August 2020 without language restrictions. A comprehensive search was employed in this review. An initial search on PubMed/Medline, Science Direct and Cochrane Library was carried out followed by an analysis of the text words contained in Title/Abstract and indexed terms. A second search was undertaken by combining free text words and indexed terms with Boolean operators. The third search was conducted with the reference lists of all identified reports and articles for additional studies. Finally, an additional and grey literature search was conducted on Google scholars. The databases were searched with the following search terms using PICO strategy by combining with AND, OR Boolean operators as COVID-19 OR coronavirus OR SARS-CoV-2 AND surgery OR operation OR preoperative OR perioperative OR postoperative AND outcomes OR mortality OR death OR morbidity OR hospital stay OR complication OR infection OR ARDS AND anesthesia OR general OR regional OR spinal.

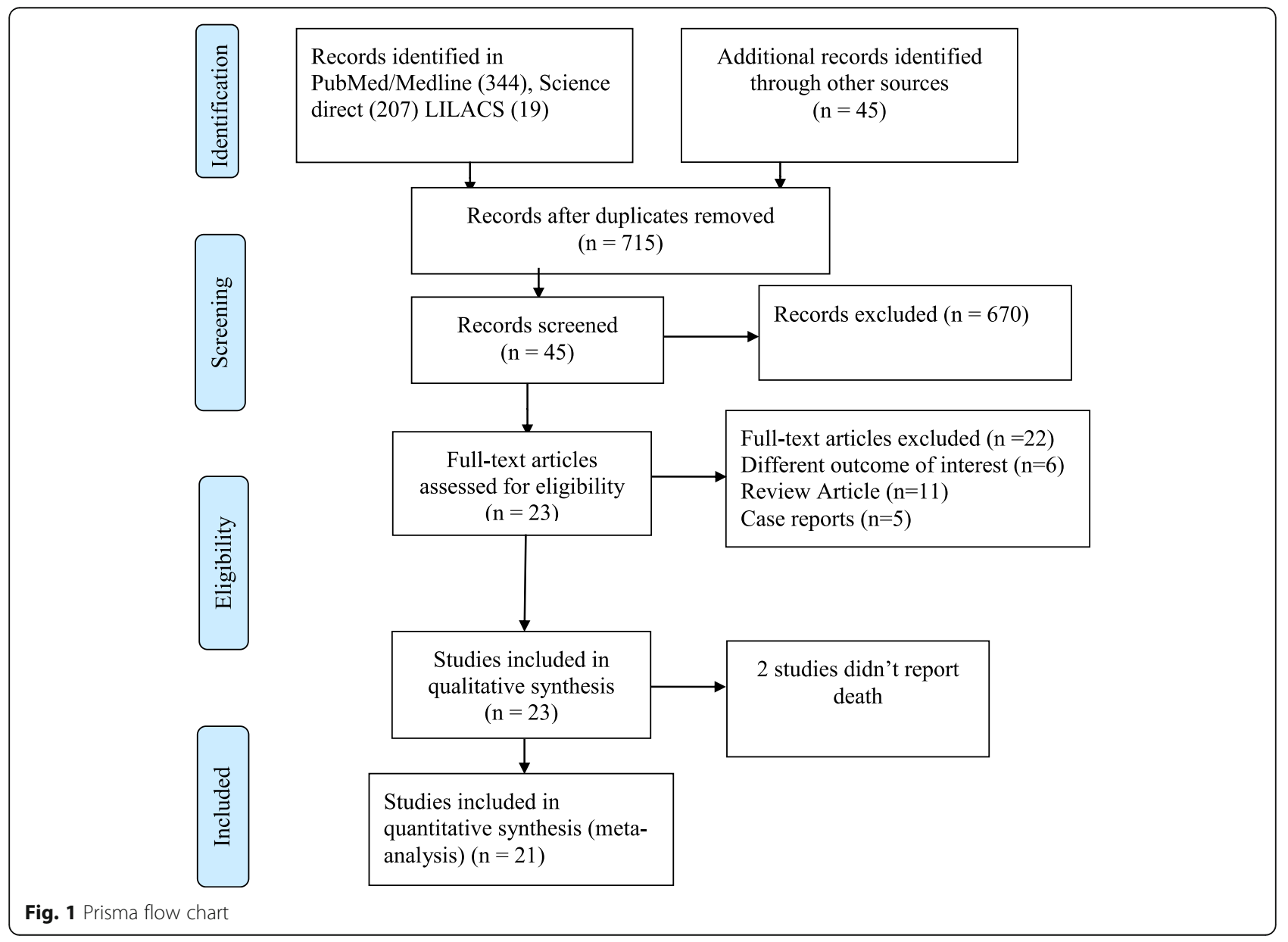


The final search results were shown with the Prisma flow diagram (Fig. 1).

\section{Data extraction}

The data from each study were extracted with two independent authors with a customized format excel sheet. The disagreements between the two independent authors were resolved by the third author. The extracted data included: Author names, country, date of publication, sample size, mortality, postoperative mechanical ventilator, the number of days on a mechanical ventilator, presence of co-morbidities, and complication. Finally, the data were then imported for analysis in $\mathrm{R}$ software version 4.0.2 and STATA 16.

\section{Assessment of methodological quality}

Articles identified for retrieval were assessed by two independent Authors for methodological quality before inclusion in the review using a standardized critical appraisal Tool adapted from the Joanna Briggs Institute (Supplemental Table 1). The disagreements between the Authors appraising the articles were resolved through discussion. Articles with average scores greater than 50 $\%$ were included for data extraction.

\section{Data analysis}

Data analysis was carried out in $\mathrm{R}$ statistical software version 4.0.2 and STATA 16. The pooled global prevalence of mortality, comorbidity, and complication among surgical patients with COVID-19 was determined with a random effect model as there was substantial heterogeneity. The Heterogeneity among the included studies was checked with forest plot, $\mathrm{X}^{2}$ test, $\mathrm{I}^{2}$ test, and the $p$ values. Substantial heterogeneity among the included studies was investigated with subgroup analysis.

Publication bias was checked with a funnel plot and the objective diagnostic test was conducted with Egger's correlation, Begg's regression tests, and Trim and fill method. Furthermore, moderator analysis was carried out to identify the independent predictors of mortality among corona cases.

\section{Results}

\section{Selection of studies}

A total of 715 articles were identified from different databases and 45 articles were selected for evaluation after the successive screening. Twenty-three articles with 2947 participants were included and the rest were excluded with reasons [34, 37-40, 56, 59-74] (Fig. 1).

Table 1 Description of included studies

\begin{tabular}{|c|c|c|c|c|c|c|c|}
\hline Author & Study period & Country & sample & Category & Urgency & quality & $\mathrm{P}(95 \% \mathrm{Cl}$ \\
\hline Bhangu et al. & Jan 1 to March 31, 2020 & UK & 1128 & Any & Any & Low risk & $24[21,26]$ \\
\hline Cai et al. [53] & February, 2020 & China & 7 & Any & Any & Low risk & $43[10,82]$ \\
\hline Casanova et al. [28] & March 11 to May 15, 2020 & Portugal & 148 & Cardiac & Emergency & Low risk & $1[0,5]$ \\
\hline Cheung et al. [75] & March 1 to May 22, 2020 & USA & 10 & Orthopedics & Emergency & Low risk & $10[0,45]$ \\
\hline Doglietto et al. [76] & Feb 1, April 23 & Italy & 41 & Any & Any & Low risk & $20[9,35]$ \\
\hline Dursun et al. [30] & March 10 to May 20, 2020 & Turkey & 200 & Gynecology & Elective & Low risk & $12[8,17]$ \\
\hline Egol et al. [36] & Feb 1 to April 15, 2020 & USA & 253 & Orthopedics & Elective & Low risk & $7[4.11]$ \\
\hline Kayani et al. [44] & Feb 1 to April, 2020 & UK & 82 & Orthopedics & Elective & Low risk & $30[21,42]$ \\
\hline LeBrun et al. [54] & March 20 to April 24, 2020 & USA & 9 & Orthopedics & Any & Low risk & $78[40,97]$ \\
\hline Lei et al. [77] & Jan 1 to Feb 5, 2020 & China & 34 & Any & Any & Low risk & $21[9,38]$ \\
\hline Li et al. [78] & Jan 1 to Feb 5, 2020 & China & 54 & Any & Emergency & Low risk & $15[7,27]$ \\
\hline Macey et al. [65] & Dec to March 2020 & UK & 76 & Orthopedics & Any & Low risk & $28[18,39]$ \\
\hline Martino et al. [79] & Feb 17 to March 31, 2020 & Spain & 15 & Any & Any & Low risk & $20[4,48]$ \\
\hline Mi et al. [80] & Jan 1 to Feb 27,2020 & China & 3 & Orthopedics & Any & Low risk & $20[4,48]$ \\
\hline Pai et al. [32] & March 24 to May 31, 2020 & India & 184 & Any & Elective & Low risk & $20[14,26]$ \\
\hline Peng et al. [55] & January 2020 & China & 11 & Thoracic & Any & Low risk & $27[6,61]$ \\
\hline Rajasekaran et al. [27] & March 12 to May 12, 2020 & UK & 56 & Orthopedics & Any & Low risk & $4[0,12]$ \\
\hline Santiago et al. [81] & March to May, 2020 & Spain & 126 & Gynecology & Elective & Low risk & $12[7,19]$ \\
\hline Seeliger et al. [27] & March 1 to May 23, 2020 & France & 13 & Any & Emergency & Low risk & $92[64,100]$ \\
\hline Sobti et al. [51] & March 1 to May 31, 2020 & UK & 206 & Orthopedics & Any & Low risk & $4[2,8]$ \\
\hline Stevenson et al. [82] & March 4 to May 22, 2020 & UK & 100 & Orthopedics & Elective & Low risk & $7[3,14]$ \\
\hline Stoneham et al. [57] & March 1 to June 12,020 & UK & 48 & Orthopedics & Elective & Low risk & - \\
\hline Zhang et al. [52] & Jan 1 to March 20, 2020 & China & 133 & Obstetrics & Both & Low risk & - \\
\hline
\end{tabular}




\section{Description of included studies}

Twenty-three Articles with 2947 participants were included in the review while twenty-one studies were included in the meta-analysis for the prevalence of mortality. Studies with the prevalence of mortality and/ or prevalence of comorbidity and prevalence of complications among surgical patients with COVID-19 were included and the characteristics of each included studies were described in (Table 1) and the rest were excluded with reasons.

The included studies were published from December 16,2019 , to June 1,2020 , with sample sizes, ranged from 3 to 1128 . The mean $( \pm \mathrm{SD})$ ages of the included studies varied from $33.7 \pm 2.75$ to $85 \pm 8.75$ years.

The majority of the included studies were conducted United Kingdom (7), China (6), USA (3), and Spain (2) [23, 26, 83-102]. Five studies were conducted in India, Italy, France, Portugal, and Turkey. Twenty-one of the included studies reported the prevalence of mortality among surgical patients with COVID-19 while two of the included studies didn't report the prevalence of mortality among surgical COVID-19 patients in the hospital. The prevalence of mortality in surgical patients with
COVID-19 from the included studies varied from 1 to $92 \%$.

Ten studies with 2134 participants reported the prevalence of comorbidity including hypertension, diabetes mellitus, cardiovascular disease, and dementia as the major comorbidity among surgical patients with COVID-19 while ten studies with 1920 participants reporting the prevalence of complications including pulmonary, acute kidney injury, myocardial Infarction, Thromboembolic disease, infection, and deep wound infection as the major complications.

The prevalence of ICU admission was reported in ten of the included studies while the overall length of hospital stay was reported in thirteen of the included studies.

\section{Meta-analysis}

\section{Global prevalence of perioperative mortality}

Twenty-one studies reported the prevalence of perioperative mortality among surgical patients with COVID-19. The pooled prevalence of perioperative mortality was 20\% (95\% CI: 15 to 26, 21 studies, and 2756 participants) (Fig. 2).

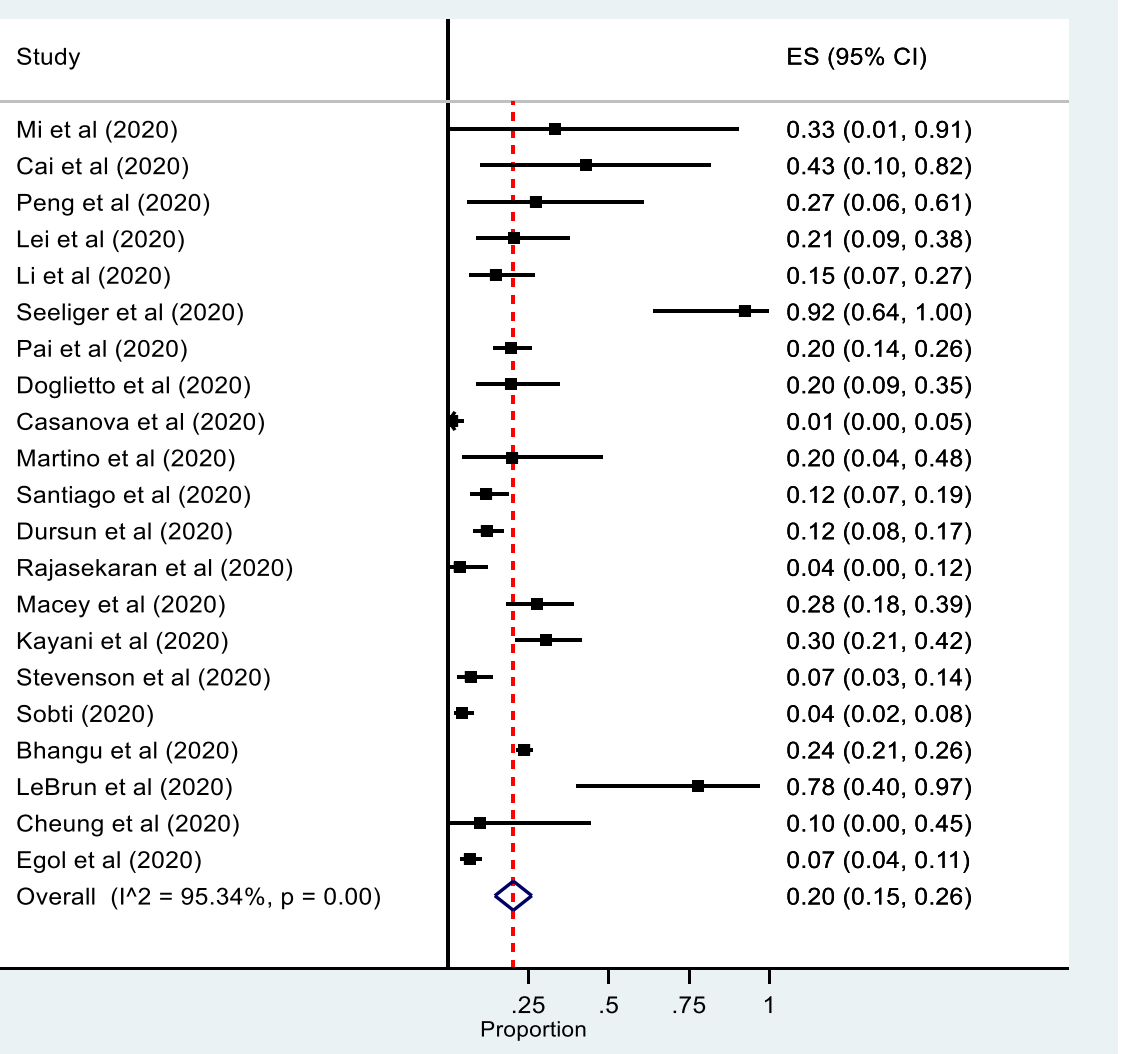

Fig. 2 Forest plot for the prevalence of mortality among hospitalized patients with COVID: The mid-point of each line illustrates the prevalence; the horizontal line indicates the confidence interval, and the diamond shows the pooled prevalence 


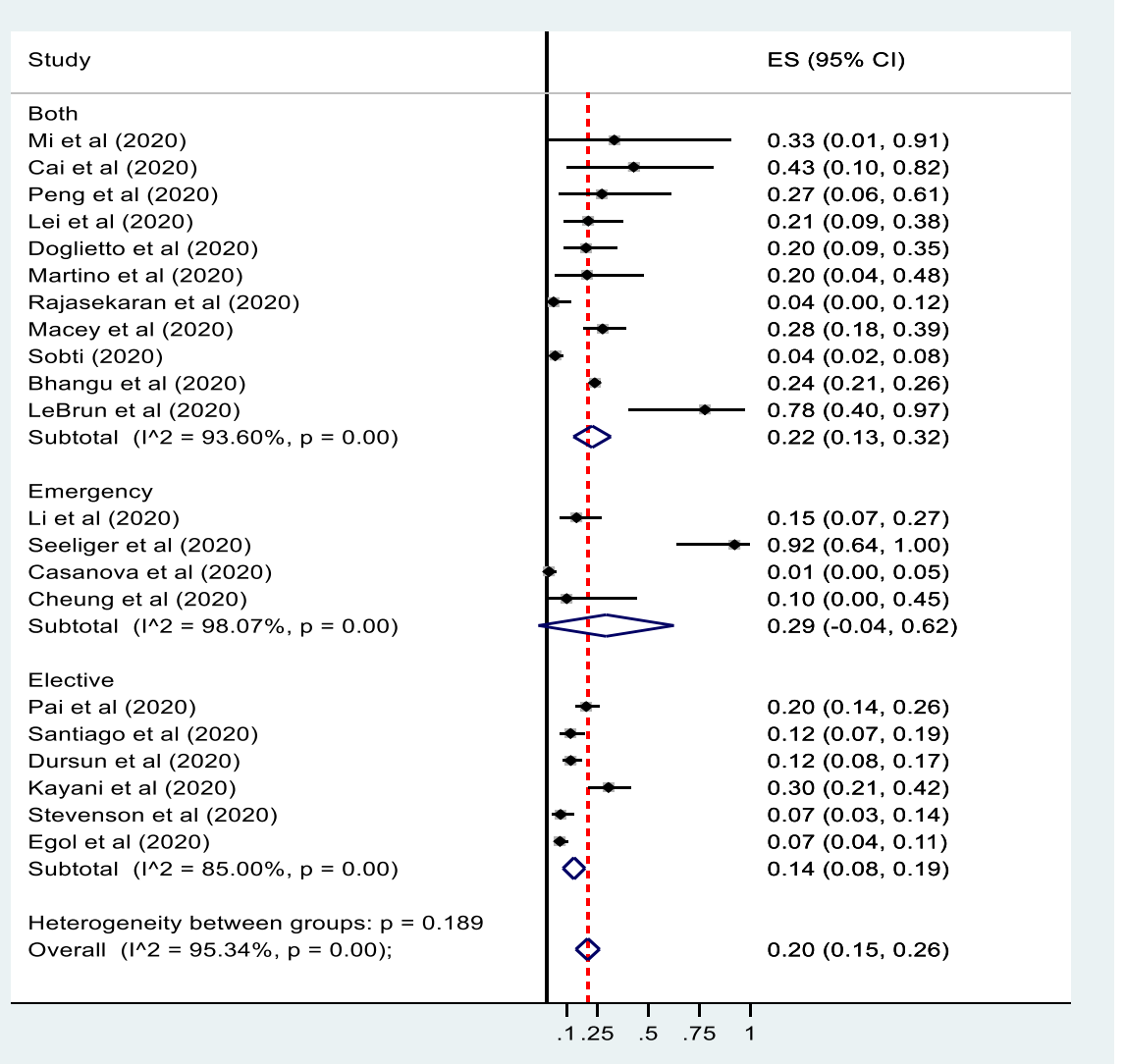

Fig. 3 Forest plot for the subgroup analysis of the prevalence of perioperative mortality among surgical patients with COVID-19 by the urgency of surgery: The midpoint of each line illustrates the prevalence; the horizontal line indicates the confidence interval, and the diamond shows the pooled prevalence. Forest plot for the prevalence of perioperative morbidity among surgical patients with COVID-19: The midpoint of each line illustrates the prevalence; the horizontal line indicates the confidence interval, and the diamond shows the pooled prevalence

The sub-group analysis was conducted by country, surgical category, and urgency of surgery. The subgroup analysis revealed that perioperative mortality was the highest among emergency surgical patients, 29\% (95\% confidence interval (CI):-4 to 62\%) (Fig. 3). The perioperative mortality among surgical patients with COVID-19 was found to be higher in France followed by the USA, 92\% (95\% confidence interval (CI): 64 to 100) and $29 \%$ (95\% confidence interval $(\mathrm{CI}):-4$ to 62 ) respectively (Supplemental Figure 1). Besides, the perioperative mortality was the highest among any surgical category followed by Orthopedics (Supplemental Figure 2).

\section{Prevalence of perioperative morbidity}

The meta-analysis revealed that the prevalence of perioperative morbidity among surgical patients with COVID-19 was 18\% (95\% CI: 10 to 25,10 studies, 2134 participants) (Fig. 3). The sub-group analysis revealed that dementia, DM, and hypertension were the most common comorbidities among surgical patients with COVID-19, 78\% (95\% confidence interval (CI):40 to 97),
20\% (95\% confidence interval (CI): 9 to 35 ) and $15 \%$ (95\% confidence interval (CI):4 to 25 ) respectively (Supplemental Figure 3).

\section{Prevalence of perioperative complication}

The pooled prevalence of perioperative complications was estimated by taking the commonest reported complication among others. The meta-analysis showed that the pooled prevalence of perioperative complications among surgical patients with COVID-19 was 14\% (95\% confidence interval (CI):7 to 22, ten studies, and 1920) participants (Fig. 4). The subgroup analysis revealed that Thromboembolic complication, infection, and pulmonary complications were the most common perioperative complications among surgical patients with COVID-19 (Supplemental Figure 4).

\section{Mean duration of hospitalization}

The pooled mean duration of hospitalization was estimated from included studies mean duration of hospitalization. The meta-analysis revealed that the 

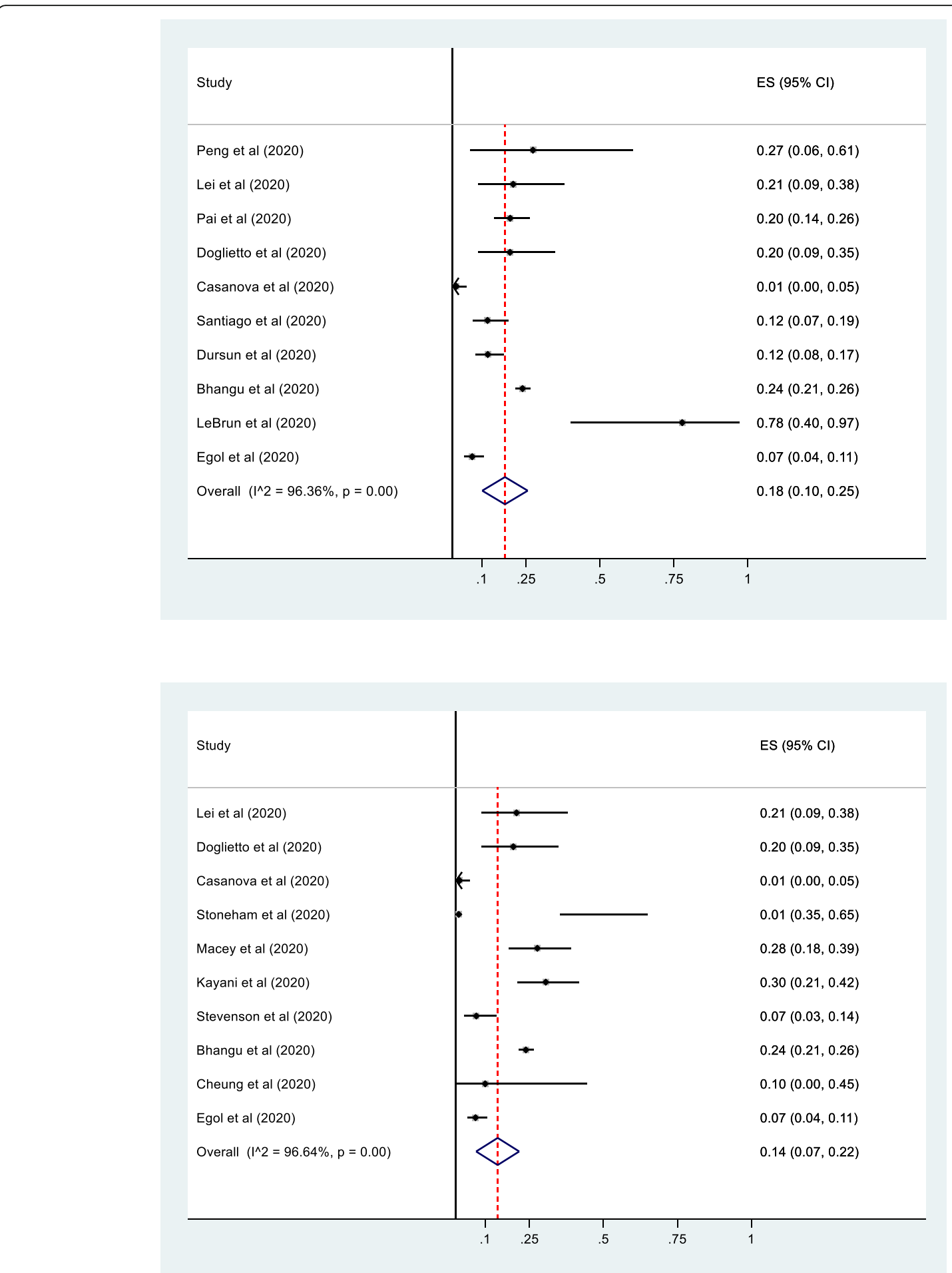

Fig. 4 Forest plot for the prevalence of perioperative complication among surgical patients with COVID-19: The midpoint of each line illustrates the prevalence; the horizontal line indicates the confidence interval, and the diamond shows the pooled prevalence

mean duration of Hospitalization was 10.55 (95\% confidence interval (CI): 8.08 to $13.03,13$ studies, 2269 participants) (Fig. 5).

\section{Rate of postoperative ICU admission}

The meta-analysis revealed that the rate postoperative ICU admission among surgical patients with COVID-19 
Study

ID

$\mathrm{ES}(95 \% \mathrm{Cl})$

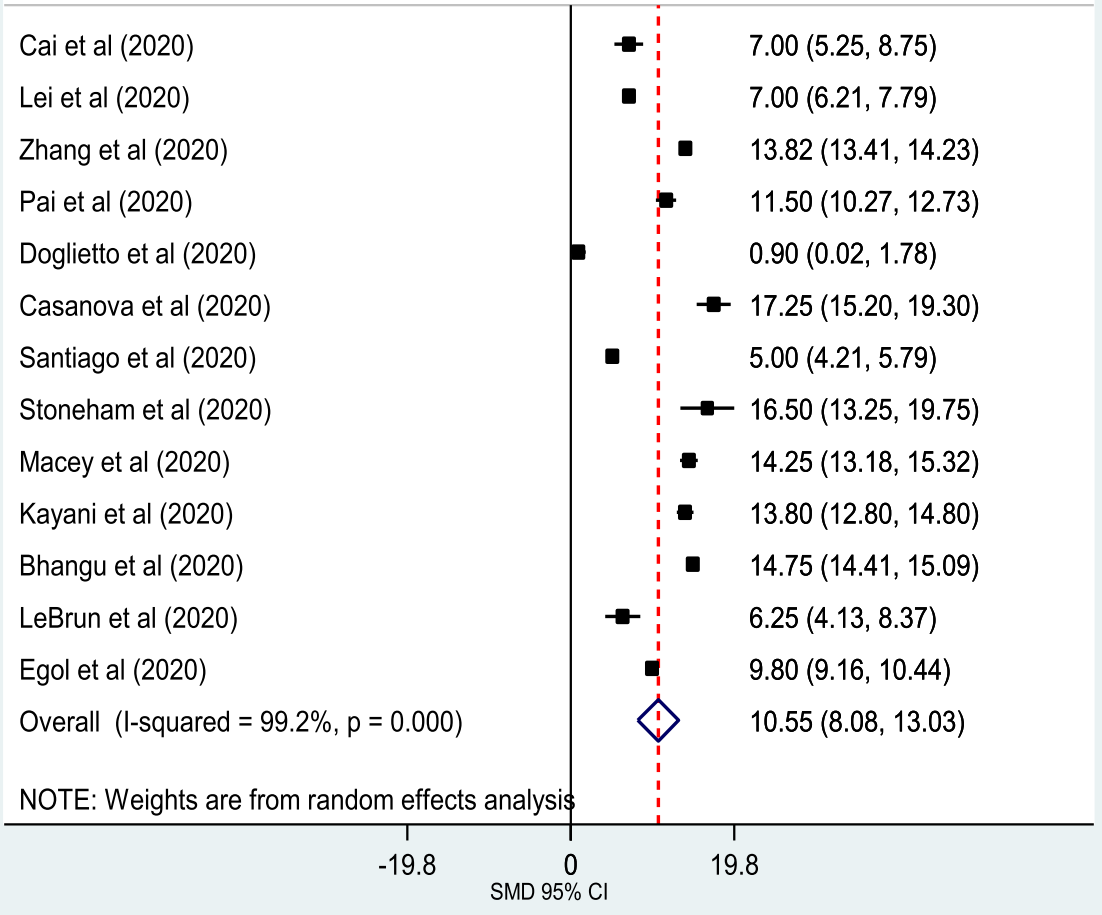

Fig. 5 Forest plot for the length of hospital stay among surgical patients with COVID-19: The midpoint of each line illustrates the prevalence; the horizontal line indicates the confidence interval, and the diamond shows the pooled prevalence

was $15 \%$ (95\% confidence interval (CI):10 to 21,10 studies, 983 participants) (Fig. 6).

\section{Prevalence of clinical presentation}

Plenty of clinical manifestations were mentioned in included studies including fever, dry cough, dyspnea, sore throat, and diarrhea. The prevalence of clinical presentation among surgical patients with COVID-19 was 26\% (95\% confidence interval (CI): 14 to 39,9 studies, and 1461 participants) (Fig. 7).

\section{Meta-regression}

The meta-analysis showed a substantial heterogeneity between the included studies which entails metaregression to identify the sources of heterogeneity. Regression Analysis was run for perioperative outcomes with mean age, length of hospital stay, and urgency of surgery moderators. However, none of the moderators showed significant association $(P$-Value $>0.05)$.
Sensitivity analysis and publication bias

Sensitivity analysis was conducted to identify the most influential study on the pooled summary effect and we didn't find a significant influencing summary effect. The funnel plot didn't show significant publication bias. Besides, egger's regression and Begg's correlation rank correlation failed to show a significant difference $(p=0.339$ and $p=2.862$ ) respectively (Fig. 8).

\section{Discussion}

The meta-analysis revealed that the global prevalence of perioperative mortality among surgical patients with COVID-19 was 20\% (95\% CI: 15 to 26). The sub-group analysis showed that perioperative mortality among COVID-19 patients was very high in patients with emergency surgery, and among studies that included different surgical categories. However, the prevalence of perioperative mortality among COVID-19 patients was the highest in patients with orthopedics surgical procedures. This discrepancy could be explained by the inclusion of 


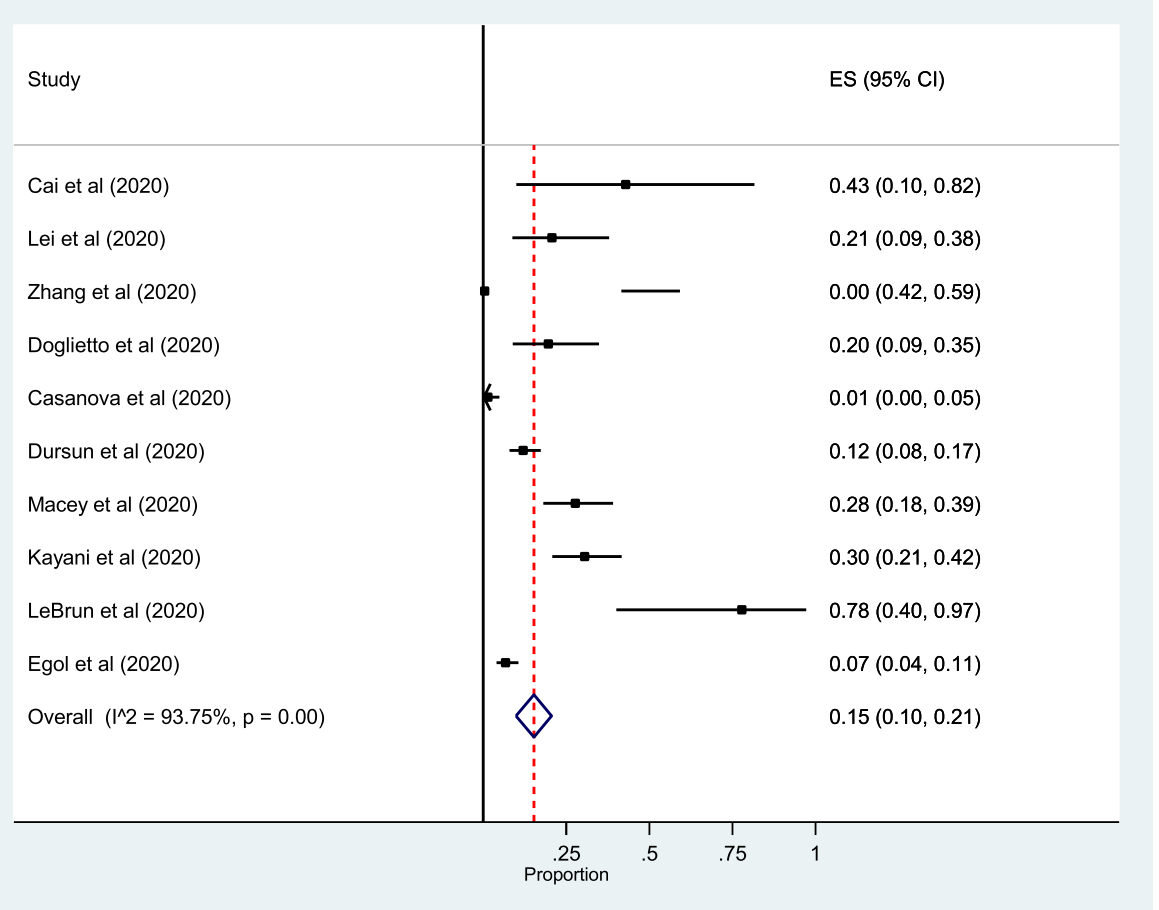

Fig. 6 Forest plot for rates postoperative ICU admission among surgical patients with COVID-19: The midpoint of each line illustrates the prevalence; the horizontal line indicates the confidence interval, and the diamond shows the pooled prevalence

low powered included studies in the case of any surgical procedures.

The lower prevalence of perioperative mortality among orthopedic patients compared to other surgical procedures could be because these patients underwent the surgical procedure under spinal anesthesia which decreases airway manipulation, aspiration, postoperative delirium, thromboembolic disease and also improves rapid oral intake and early ambulation.

The meta-analysis showed that the prevalence of comorbidity among surgical patients was with COVID-19 was $18 \%$ (95\% CI: 10 to 25 ) which is in line with the results of included studies [28, 30, 36, 54, 76, 77, 81]. The subgroup analysis showed that dementia was the most prevalent comorbidity followed by hypertension and Diabetes Mellitus. However, the finding of this study was contrary to other studies conducted on the prevalence of comorbidities among patients with COVID-19 where hypertension was the most prevalent comorbidity among patients with COVID-19 [28, 32, 77]. This discrepancy might be explained by the inclusion of only one study in this meta-analysis that reported a high prevalence of dementia compared to other comorbidities.

Many complications were mentioned in the literature in patients with COVID-19 who underwent surgical procedures $[28,36,44,45,57,75-77,82]$. The meta- analysis revealed that thromboembolic disease, pulmonary complications, infection, and deep wound infection were the commonest perioperative complications. All these complications were more likely associated with low immunity and prolonged immobility while patients were on a mechanical ventilator.

The meta-analysis showed that the pooled mean duration of hospitalization was 10.55 (95\% confidence interval (CI): 8.08 to 13.03 ) which is comparable with the findings of the included studies [28, 36, 44, 45, 57, 75-77, 82].

\section{Quality of evidence}

The methodological quality of included studies was moderate to high quality as depicted with Joanna Briggs Institute assessment tool for meta-analysis of observational studies. However, substantial heterogeneity associated with dissimilarities of included studies in sample size, design, and location could affect the allover quality of evidence.

\section{Limitation of the study}

The meta-analysis included studies with moderate to high methodological quality. However, some of the included studies were low powered and the majority of studies included in this review didn't report data on comorbidity and risk factors to investigate the independent predictors. Besides, there were a limited number of studies in some countries and it would be difficult to provide 


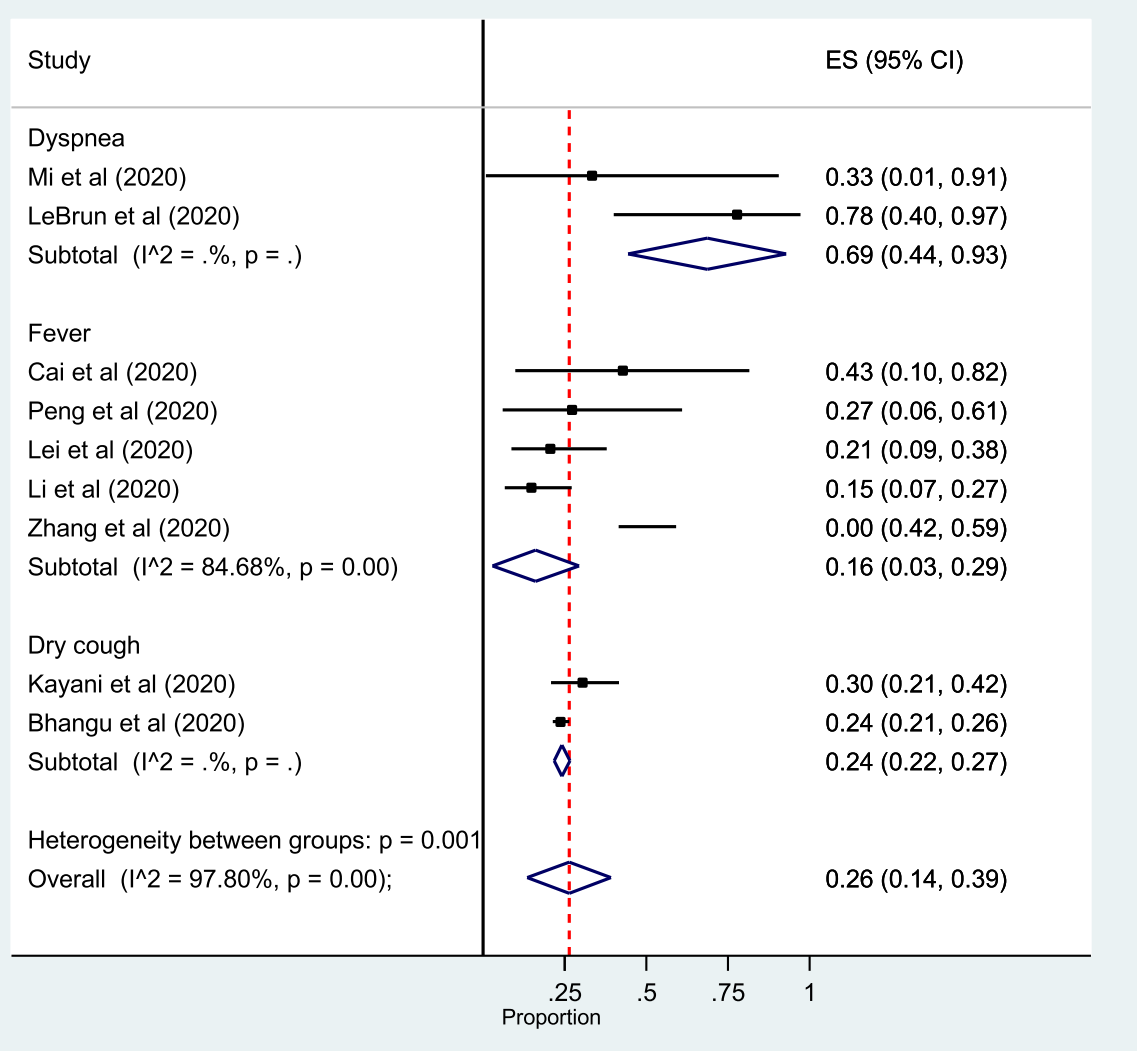

Fig. 7 Forest plot for subgroup analysis of the prevalence of clinical presentation among surgical patients with COVID-19 by types of presentations: The midpoint of each line illustrates the prevalence; the horizontal line indicates the confidence interval, and the diamond shows the pooled prevalence

conclusive evidence with results pooled from fewer studies.

\section{Implication for practice}

Body of evidence revealed that perioperative mortality; morbidity and complications were very high among patients with COVID-19. This is a huge challenge especially in resource-limited settings where there are a limited number of ICU beds, mechanical ventilator, integrated patient monitor, skilled professionals combined with malnutrition, and communicable disease. Therefore, a mitigating strategy is required by different stakeholders to combat the catastrophic impacts of the COVID-19 pandemic through creating awareness about

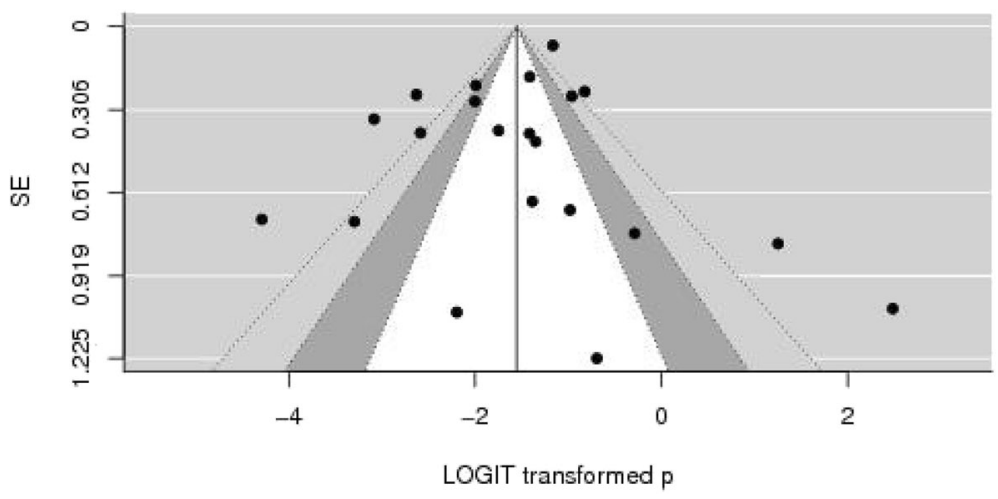

Fig. 8 Funnel plot to assess publication bias. The vertical line indicates the effect size whereas the diagonal line indicates the precision of individual studies with a $95 \%$ confidence interval 
preventive measures, implementing protocols for supportive management, management of comorbidities, and prevention of complications.

\section{The implication for further research}

The meta-analysis revealed that perioperative mortality, complication, rate of ICU admission among surgical COVD-19 patients was very high. However, the included studies were too heterogeneous, low powered, and crosssectional studies also don't show a temporal relationship between mortality and its determinants. Therefore, further observational and randomized controlled trials are required.

\section{Conclusion}

The meta-analysis revealed that the prevalence of mortality, perioperative complication, and rate of intensive care unit admission was very high. The meta-analysis showed that there is one death for every five COVID-19 patients undergoing surgical procedures which entail mitigating strategies to decrease perioperative mortality, infection transmission to health care workers, and nonCOVID-19 patients; provide less risky anesthetic techniques and alternative management other than surgical procedures. Besides, there have to be guidelines to operate or not to operate high patients with COVID-19 for elective and urgent surgeries.

\section{Supplementary information}

Supplementary information accompanies this paper at https://doi.org/10. 1186/s13037-020-00262-6.

Additional file 1: Supplemental Table 1. methodological quality of

included studies

Additional file 2: Supplemental Figure 1. Forest plot for the global prevalence of perioperative mortality among surgical patients with COVID-19 by types of surgery: The midpoint of each line illustrates the prevalence; the horizontal line indicates the confidence interval, and the diamond shows the pooled prevalence.

Additional file 3: Supplemental Figure 2. Forest plot for the global prevalence of perioperative mortality among surgical patients with COVID-19 by urgency of surgery: The midpoint of each line illustrates the prevalence; the horizontal line indicates the confidence interval, and the diamond shows the pooled prevalence.

Additional file 4: Supplemental Figure 3. Forest plot for the subgroup analysis of prevalence of perioperative comorbidity among surgical patients with COVID-19 by types of comorbidity: The midpoint of each line illustrates the prevalence; the horizontal line indicates the confidence interval, and the diamond shows the pooled prevalence.

Additional file 5: Supplemental Figure 4. Forest plot for sub-group analysis of prevalence of perioperative complication among surgical patients with COVID-19 by types of complication: The midpoint of each line illustrates the prevalence; the horizontal line indicates the confidence interval, and the diamond shows the pooled prevalence

\section{Acknowledgments}

The authors would like to acknowledge Dilla University for technical support and encouragement to carry out the project.

\section{Authors' contributions}

$\mathrm{SA}$ and $\mathrm{BM}$ conceived the idea design of the project. SA, BM, and BB involved in searching strategy, data extraction, quality assessment, analysis, and manuscript preparation. The author(s) read and approved the final manuscript.

Funding

No funding was obtained from any organization.

\section{Availability of data and materials}

Data and material can be available where appropriate.

Ethics approval and consent to participate

Ethical clearance and approval were obtained from the ethical review board of the College of Health Science and Medicine.

Consent for publication

Not applicable.

\section{Competing interests}

The authors declare that there are no competing interests.

\section{Author details}

${ }^{1}$ Department of Anesthesiology, College of Health Sciences and Medicine, Dilla University, PO.BOX:419, Dilla, Ethiopia. ${ }^{2}$ Department of Internal Medicine, College of Health Sciences and Medicine, Dilla University, Dilla, Ethiopia. ${ }^{3}$ Department of Anesthesiology, College of Health Sciences, University of Calcutta, Kolkata, India.

Received: 7 September 2020 Accepted: 18 September 2020 Published online: 12 October 2020

\section{References}

1. Kakodkar P, Kaka N, Baig M. A comprehensive literature review on the clinical presentation, and management of the pandemic coronavirus disease 2019 (COVID-19). Cureus. 2020;12(4):e7560. https://doi.org/10.7759/cureus.7560.

2. Lechien JR, Chiesa-Estomba CM, De Siati DR, Horoi M, Le Bon SD, Rodriguez $A$, et al. Olfactory and gustatory dysfunctions as a clinical presentation of mild-to-moderate forms of the coronavirus disease (COVID-19): a multicenter European study. Eur Arch Otorhinolaryngol. 2020:1-11.

3. Lechien JR, Chiesa-Estomba CM, Place S, Van Laethem Y, Cabaraux P, Mat Q et al. Clinical and epidemiological characteristics of 1,420 European patients with mild-to-moderate coronavirus disease 2019. J Intern Med:2020.

4. Woelfel R, Corman VM, Guggemos W, Seilmaier M, Zange S, Mueller MA, et al. Clinical presentation and virological assessment of hospitalized cases of coronavirus disease 2019 in a travel-associated transmission cluster. MedRxiv. 2020; https://doi.org/10.1101/2020.03.05.20030502.

5. Asadi-Pooya AA, Simani L. Central nervous system manifestations of COVID19: a systematic review. J Neurol Sci. 2020:413:1-4.

6. Basu-Ray I, Soos MP. Cardiac Manifestations Of Coronavirus (COVID-19): StatPearls [Internet]. Treasure Island, USA: StatPearls Publishing; 2020.

7. Gu J, Han B, Wang J. COVID-19: gastrointestinal manifestations and potential fecal-oral transmission. Gastroenterology. 2020;158(6):1518-9.

8. Hajifathalian K, Krisko T, Mehta A, Kumar S, Schwartz R, Fortune B, Sharaiha $R$, on behalf of WCM-GI research group. Gastrointestinal and Hepatic Manifestations of 2019 NovelCoronavirus Disease in a Large Cohort of Infected Patients From New York: Clinical Implications. Gastroenterology. 2020; https://doi.org/10.1053/j.gastro.2020.05.010.

9. Kumar A, Arora A, Sharma P, Anikhindi SA, Bansal N, Singla V, et al. Gastrointestinal and hepatic manifestations of Corona virus Disease-19 and their relationship to severe clinical course: a systematic review and metaanalysis. Indian J Gastroenterol. 2020:1-17.

10. Mao L, Jin H, Wang M, Hu Y, Chen S, He Q, et al. Neurologic manifestations of hospitalized patients with coronavirus disease 2019 in Wuhan, China. JAMA Neurology. 2020;77(6):683-90.

11. Tang $K$, Wang $Y$, Zhang $H$, Zheng Q, Fang $R$, Sun Q. Cutaneous manifestations of the coronavirus disease 2019 (COVID-19): a brief review. Dermatol Ther. 2020;33(4):e13528. https://doi.org/10.1111/dth.13528.

12. Thakkar S, Arora S, Kumar A, Jaswaney R, Faisaluddin M, Din MAU, et al. A Systematic Review of the Cardiovascular Manifestations and Outcomes in the Setting of Coronavirus-19 Disease. medRxiv. 2020. https://doi.org/10. 1101/2020.08.09.20171330. 
13. <20200813-covid-19-sitrep-206.pdf>

14. Nachega J, Seydi M, Zumla A. The late arrival of coronavirus disease 2019 (COVID-19) in Africa: mitigating Pan-continental spread. Clin Infect Dis. 2020; 71(15):875-8.

15. Paintsil E. COVID-19 threatens health systems in sub-Saharan Africa: the eye of the crocodile. J Clin Invest. 2020;130(6):2741-44. https://doi.org/10.1172/ JCl138493.

16. Emanuel EJ, Persad G, Upshur R, Thome B, Parker M, Glickman A, et al. Fair allocation of scarce medical resources in the time of Covid-19. N Engl J Med 2020;382:2049-55. https://doi.org/10.1056/NEJMsb2005114.

17. McKibbin WJ, Fernando R. The global macroeconomic impacts of COVID-19: seven scenarios; 2020.

18. Nicola M, Alsafi Z, Sohrabi C, Kerwan A, Al-Jabir A, losifidis C, et al. The socio-economic implications of the coronavirus pandemic (COVID-19): A review. Int I Surg. 2020;78:185.

19. Spinelli A, Pellino G. COVID-19 pandemic: perspectives on an unfolding crisis. Br J Surg. 2020. https://doi.org/10.1002/bjs.11627.

20. Walker PG, Whittaker C, Watson OJ, Baguelin M, Winskill P, Hamlet A, et al. The impact of COVID-19 and strategies for mitigation and suppression in low-and middle-income countries. Science. 2020;369(6502):413-22. https:/ doi.org/10.1126/science.abc0035.

21. Bong C-L, Brasher C, Chikumba E, McDougall R, Mellin-Olsen J, Enright A. The COVID-19 pandemic: effects on low-and middle-income countries, Anesth Analg. 2020.

22. Da'ar OB, Haji M, Jradi H. Coronavirus disease 2019 (COVID-19): potential implications for weak health systems and conflict zones in the Middle East and North Africa region. Int J Health Plann Manag. 2020;35(4):1-6.

23. Guan W-J, et al. Comorbidity and its impact on 1590 patients with Covid-19 in China: a nationwide analysis. Eur Respir J. 2020;55:2000547. https://doi.org/10. 1183/13993003.00547-2020.

24. Mao R, Liang J, Shen J, Ghosh S, Zhu L-R, Yang H, et al. Implications of COVID-19 for patients with pre-existing digestive diseases. Lancet Gastroenterol Hepatol. 2020;5(5):426-8.

25. Richardson S, Hirsch JS, Narasimhan M, Crawford JM, McGinn T, Davidson $\mathrm{KW}$, et al. Presenting characteristics, comorbidities, and outcomes among 5700 patients hospitalized with COVID-19 in the New York City area. JAMA. 2020;323(20):2052-9. https://doi.org/10.1001/jama.2020.6775.

26. Yang J, Zheng Y, Gou X, Pu K, Chen Z, Guo Q, et al. Prevalence of comorbidities in the novel Wuhan coronavirus (COVID-19) infection: a systematic review and meta-analysis. Int J Infect Dis. 2020;94:91-5.

27. Seeliger B, Philouze G, Cherkaoui Z, Felli E, Mutter D, Pessaux P. Acute abdomen in patients with SARS-CoV-2 infection or co-infection. Langenbeck's Arch Surg. 2020:1-6.

28. Casanova J, Pissarra D, Costa R, Salgueiro E, Pinho P. Cardiothoracic surgery during the Covid-19 pandemic: perioperative care, safety, and surgical results. J Card Surg. 2020;35(9):1-6.

29. Driggin E, Madhavan MV, Bikdeli B, Chuich T, Laracy J, Biondi-Zoccai G, et al. Cardiovascular considerations for patients, health care workers, and health systems during the COVID-19 pandemic. J Am Coll Cardiol. 2020;75(18):2352-71.

30. Dursun P, Dervisoglu H, Daggez M, Turan T, Kiliç FM, Tekin Ö, et al. Performing gynecologic cancer surgery during the COVID-19 pandemic in Turkey: A multicenter retrospective observational study. IJOG. 2020;151(1): 34-8 https://doi.org/10.1002/ijgo.13296.

31. Luceri F, Morelli I, Accetta R, Mangiavini L, Maffulli N, Peretti GM. Italy and COVID-19: the changing patient flow in an orthopedic trauma center emergency department: BioMed Central; 2020.

32. Pai E, Chopra S, Mandloi D, Upadhyay AK, Prem A, Pandey D. Continuing surgical care in cancer patients during the nationwide lockdown in the COVID19 pandemic - perioperative outcomes from a tertiary care cancer center in India. J Surg Oncol. 2020;122(5):1-6 https://doi.org/10.1002/jso.26134.

33. Søreide $K$, Hallet J, Matthews J, Schnitzbauer A, Line P, Lai P, et al. Immediate and long-term impact of the COVID-19 pandemic on delivery of surgical services. Br J Surg. 2020;107(10):1250-6 https://doi.org/10.1002/bjs. 11670.

34. Aziz H, Filkins A, Kwon YK. Review of COVID-19 outcomes in surgical patients. Am Surg. 2020;86(7):741-5 https://doi.org/10.1177\%2F000313482 0934395.

35. Chappidi MR, Kates M, Stimson C, Johnson MH, Pierorazio PM, Bivalacqua TJ. Causes, timing, hospital costs and perioperative outcomes of index vs nonindex hospital readmissions after radical cystectomy: implications for regionalization of care. J Urol. 2017;197(2):296-301.
36. Egol KA, Konda SR, Bird ML, Dedhia N, Landes EK, Ranson RA, et al. Increased mortality and major complications in hip fracture care during the COVID-19 pandemic: a New York City perspective. J Orthop Trauma. 2020; 34(8):395-40. https://doi.org/10.1097/bot.0000000000001845.

37. Gao Y, Xi H, Chen L. Emergency surgery in suspected COVID-19 patients with acute abdomen: case series and perspectives. Ann Surg. 2020;272(1). https://doi.org/10.1097/SLA.0000000000003961.

38. Greenland JR, Michelow MD, Wang L, London MJ. COVID-19 InfectionImplications for perioperative and critical care physicians. Anesthesiology. 2020;132(6):1346-61.

39. Nzara R, Rybin D, Doros G, Didato S, Farber A, Eslami MH, et al. Perioperative outcomes in patients requiring iliac conduits or direct access for endovascular abdominal aortic aneurysm repair. Ann Vasc Surg. 2015;29(8):1548-53.

40. O'Leary MP, Choong KC, Thornblade LW, Fakih MG, Fong Y, Kaiser AM. Management considerations for the surgical treatment of colorectal Cancer during the global Covid-19 pandemic. Ann Surg. 2020;272(2):e98-e105.

41. Patel V, Jimenez E, Cornwell L, Tran T, Paniagua D, Denktas AE, et al. Cardiac surgery during the COVID-19 pandemic: perioperative considerations and triage recommendations. J Am Heart Assoc. 2020;9:e017042.

42. Zar HJ, Dawa J, Fischer GB, Castro-Rodriguez JA. Challenges of COVID-19 in children in low-and middle-income countries. Paediatr Respir Rev. 2020;35: 70-4 https://dx.doi.org/10.1016\%2Fj.prrv.2020.06.016.

43. Collaborative C. Global guidance for surgical care during the COVID-19 pandemic. Br J Surg. 2020;107(9):1097-103 https://doi.org/10.1002/bjs.11646.

44. Kayani B, Onochie E, Patil V, Begum F, Cuthbert R, Ferguson D, et al. The effects of COVID-19 on perioperative morbidity and mortality in patients with hip fractures: a multicentre cohort study. Br J Surg. 2020;107(9):1097-103. https://doi.org/10.1002/bjs.11646.

45. Macey AR, Butler J, Martin SC, Tan TY, Leach WJ, Jamal B. 30-day outcomes in hip fracture patients during the COVID-19 pandemic compared to the preceding year. Bone Joint Open. 2020;1(7):415-9.

46. Neethirajan SG, Manickam A. Scheduling elective surgeries following COVID19: Challenges ahead. United Kingdom: J Anaesthesiol Clin Pharmacol. [Epub ahead of print] [cited 2020 Sep 22]. India, Available from: http://www. joacp.org/preprintarticle.asp?id=290701.

47. Ademuyiwa AO, Bekele A, Berhea AB, Borgstein E, Capo-Chichi N, Derbew $M$, et al. COVID-19 preparedness within the surgical, obstetric, and anesthetic ecosystem in sub-Saharan Africa. Ann Surg. 2020;272(1):e9-e13. https://doi.org/10.1097/SLA.0000000000003964.

48. Hopman J, Allegranzi B, Mehtar S. Managing COVID-19 in low-and middleincome countries. JAMA. 2020;323(16):1549-50.

49. Ma X, Vervoort D, Reddy CL, Park KB, Makasa E. Emergency and essential surgical healthcare services during COVID-19 in low-and middle-income countries: a perspective. Int J Surg. 2020;79:43-6. https://dx.doi.org/10.1 016\%2Fj.ijsu.2020.05.037.

50. Oudrhiri MY, Bechri H, El Mehdi Hakkou AM, Arkha Y, El Ouahabi A. Neurosurgical patients' management during the COVID-19 pandemic -an institutional report from an African neurosurgical center. Neurosurgery. 2020.

51. Sobti A, et al. Outcome of trauma and orthopaedic surgery at a UK District General Hospital during the Covid-19 pandemic. J Clin Orthop Trauma. 2020; https://doi.org/10.1016/j.jcot.2020.06.042

52. Zhang Y, Chen R, Wang J, Gong Y, Zhou Q, Cheng H-h, Xia Z-y, Chen X, Meng $\mathrm{Q}-\mathrm{t}, \mathrm{Ma} \mathrm{D}$, et al. Anaesthetic managment and clinical outcomes of parturients with COVID-19: a multicentre, retrospective, propensity score matched cohort study. medRxiv. 2020. https://doi.org/10.1101/2020.03.24.20042176.

53. Cai Y, Hao Z, Gao Y, Ping W, Wang Q, Peng S, et al. COVID-19 in the perioperative period of lung resection: a brief report from a single thoracic surgery department in Wuhan. China. J Thorac Oncol. 2020;15(6):1065-72. https://doi.org/10.1016/j.jtho.2020.04.003.

54. LeBrun DG, Konnaris MA, Ghahramani GC, Premkumar A, DeFrancesco CJ, Gruskay JA, et al. Hip fracture outcomes during the COVID-19 pandemic: early results from New York. J Orthop Trauma. 2020;34(8). https://doi.org/10. 1097/BOT.0000000000001849.

55. Peng S, Huang L, Zhao B, Zhou S, Braithwaite I, Zhang N, et al. Clinical course of coronavirus disease 2019 in 11 patients after thoracic surgery and challenges in diagnosis. J Thorac Cardiovasc Surg. 2020;160(2):585-93. https://doi.org/10.1016/j.jtcvs.2020.04.005.

56. Stensland KD, Morgan TM, Moinzadeh A, Lee CT, Briganti A, Catto JW, et al. Considerations in the triage of urologic surgeries during the COVID-19 pandemic. Eur Urol. 2020;77(6):663. 
57. Stoneham AC, Apostolides M, Bennett PM, Hillier-Smith R, Witek AJ, Goodier $\mathrm{H}$, et al. Early outcomes of patients undergoing total hip arthroplasty for trauma during COVID-19. Bone Joint Open. 2020;1(7):438-42.

58. Moher D, Liberati A, Tetzlaff J, Altman DG, Group P. Preferred reporting items for systematic reviews and meta-analyses: the PRISMA statement. PLoS Med. 2009:6(7):e1000097.

59. Aminian A, Kermansaravi M, Azizi S, Alibeigi P, Safamanesh S, Mousavimaleki A, et al. Bariatric surgical practice during the initial phase of COVID-19 outbreak. Obes Surg. 2020;30:3624-7.

60. Bauer ME, Bernstein K, Dinges E, Delgado C, El-Sharawi N, Sultan P, et al. Obstetric anesthesia during the COVID-19 pandemic. Anesth Analg. 2020; 131(1):7-15.

61. Day AT, Sher DJ, Lee RC, Truelson JM, Myers LL, Sumer BD, et al. Head and neck oncology during the COVID-19 pandemic: reconsidering traditional treatment paradigms in light of new surgical and other multilevel risks. Oral Oncol. 2020;105:1-8 https://doi.org/10.1016/j.oraloncology.2020.104684.

62. Ejaz A, Spolverato G, Kim Y, Wolfgang CL, Hirose K, Weiss M, et al. The impact of resident involvement on surgical outcomes among patients undergoing hepatic and pancreatic resections. Surgery. 2015;158(2):323-30.

63. Hage R, Steinack C, Benden C, Schuurmans MM. COVID-19 in patients with solid organ transplantation: a systematic review. Transplantology. 2020;1(1): $1-15$.

64. Kiong KL, Guo T, Yao CM, Gross ND, Hanasono MM, Ferrarotto R, et al. Changing practice patterns in head and neck oncologic surgery in the early COVID-19 era. Head Neck. 2020;42(6):1179-86.

65. Massey PA, McClary K, Zhang AS, Savoie FH, Barton RS. Orthopaedic surgical selection and inpatient paradigms during the coronavirus (COVID-19) pandemic. J Am Acad Orthop Surg. 2020;28(11):436-50. https://doi.org/10. 5435/JAAOS-D-20-00360

66. Mori M, Geirsson A, Vallabhajosyula P, Assi R. Surgical management of thoracic aortic emergency with pre-and postoperative COVID-19 disease. J Vasc Surg. 2020;72(2):408-41. https://dx.doi.org/10.1016\%2Fj.jvs.2020.04.487

67. Obek C, Doganca T, Argun OB, Kural AR. Management of prostate cance patients during COVID-19 pandemic. Prostate Cancer Prostatic Dis. 2020:1-9.

68. Sharma D, Rasmussen M, Han R, Whalin MK, Davis M, Kofke WA, et al. Anesthetic Management of Endovascular Treatment of Acute Ischemic Stroke During COVID-19 Pandemic: Consensus Statement From Society for Neuroscience in Anesthesiology \& Critical Care (SNACC): Endorsed by Society of Vascular \& Interventional Neurology (SVIN), Society of Neurolnterventional Surgery (SNIS), Neurocritical Care Society (NCS), European Society of Minimally Invasive Neurological Therapy (ESMINT) and American Association of Neurological Surgeons (AANS) and Congress of Neurological Surgeons (CNS) Cerebrovascular Section. J Neurosurg Anesthesiol. 2020;32:193-201.

69. Song SK, Choi WK, Cho MR. Surgical intervention in patients with proximal femoral fractures confirmed positive for COVID-19-a report of 2 cases. Acta Orthop. 2020:1-4.

70. Sooriakumaran P, Karnes J, Stief C, Copsey B, Montorsi F, Hammerer P, et al. A multi-institutional analysis of perioperative outcomes in 106 men who underwent radical prostatectomy for distant metastatic prostate cancer at presentation. Eur Urol. 2016;69(5):788-94.

71. Specht M, Sobti N, Rosado N, Tomczyk E, Abbate O, Ellis D, et al. Highefficiency same-Day approach to breast reconstruction during the COVID-19 crisis. Breast Cancer Res Treat. 2020:1-10.

72. Steward JE, Kitley WR, Schmidt CM, Sundaram CP. Urologic surgery and COVID-19: how the pandemic is changing the way we operate. J Endourol. 2020;34(5):541-9.

73. Stinner DJ, Lebrun C, Hsu JR, Jahangir AA, Mir HR. The orthopaedic trauma service and COVID-19: practice considerations to optimize outcomes and limit exposure. J Orthop Trauma. 2020.

74. Vanni G, Materazzo M, Pellicciaro M, Ingallinella S, Rho M, Santori F, et al. Breast cancer and COVID-19: the effect of fear on patients' decision-making process. In Vivo. 2020;34(3 suppl):1651-9.

75. Cheung ZB, Forsh DA. Early outcomes after hip fracture surgery in COVID-19 patients in New York City. J Orthop. 2020;21:291-6.

76. Doglietto F, Vezzoli M, Gheza F, Lussardi GL, Domenicucci M, Vecchiarelli L, et al. Factors associated with surgical mortality and complications among patients with and without coronavirus disease 2019 (COVID-19) in Italy. JAMA Surg. 2020;155(8):1-14. https://doi.org/10.1001/jamasurg.2020.2713.
77. Lei S, Jiang F, Su W, Chen C, Chen J, Mei W, et al. Clinical characteristics and outcomes of patients undergoing surgeries during the incubation period of COVID-19 infection. Eclinical Medicine. 2020;21:1-8.

78. Lie SA, Wong SW, Wong LT, Wong TGL, Chong SY. Practical considerations for performing regional anesthesia: lessons learned from the COVID-19 pandemic. Can J Anesth. 2020:1-8.

79. Di Martino M, Septiem JG, González RM, Nova JLM, de la Hoz Rodríguez Á, Bonito AC, et al. Cirugía electiva durante la pandemia por SARS-CoV-2 (COVID-19): análisis de morbimortalidad y recomendaciones sobre priorización de los pacientes y medidas de seguridad. CirEsp. 2020; https:// doi.org/10.1016/j.ciresp.2020.04.029.

80. Mi B, Chen L, Xiong Y, Xue H, Zhou W, Liu G. Characteristics and early prognosis of COVID-19 infection in fracture patients. J Bone Joint Surg Am. 2020;102(9):750

81. de Santiago J, Yelo C, Chereguini MF, Conde A, Galipienzo J, Salvatierra D, et al. COVID-19: gynecologic cancer surgery at a single center in Madrid. Int J Gynecol Cancer. 2020;30(8):1108-12.

82. Stevenson JD, Evans S, Morris G, et al. Mortality of high-risk orthopaedic oncology patients During the COVID-19 pandemic: A prospective cohort study. J Surg Oncol. 2020:1-4 https://doi.org/10.1002/jso.26127.

83. Cao J, Hu X, Cheng W, Yu L, Tu W-J, Liu Q. Clinical features and short-term outcomes of 18 patients with corona virus disease 2019 in intensive care unit. Intensive Care Med. 2020:1-3.

84. Chen N, Zhou M, Dong X, Qu J, Gong F, Han Y, et al. Epidemiological and clinical characteristics of 99 cases of 2019 novel coronavirus pneumonia in Wuhan, China: a descriptive study. Lancet. 2020;395(10223):507-13.

85. Cheng Y, Luo R, Wang K, Zhang M, Wang Z, Dong L, et al. Kidney disease is associated with in-hospital death of patients with COVID-19. Kidney Int. 2020.

86. Guan W-J, Ni Z-Y, Hu Y, Liang W-H, Ou C-Q, He J-X, et al. Clinical characteristics of coronavirus disease 2019 in China. N Engl J Med. 2020; 382(18):1708-20.

87. Huang C, Wang Y, Li X, Ren L, Zhao J, Hu Y, et al. Clinical features of patients infected with 2019 novel coronavirus in Wuhan. China. Lancet. 2020;395(10223):497-506.

88. Bogani G, Raspagliesi F. Minimally invasive surgery at the time of COVID-19: the OR staff needs protection. J Minim Invasive Gynecol. 2020;27(5):1221.

89. Liu W, Tao Z-W, Wang L, Yuan M-L, Liu K, Zhou L, et al. Analysis of factors associated with disease outcomes in hospitalized patients with 2019 novel coronavirus disease. Chin Med J. 2020;133(9):1032-8. https://dx.doi.org/10.1 097\%2FCM9.0000000000000775.

90. Pan A, Liu L, Wang C, Guo H, Hao X, Wang Q, et al. Association of public health interventions with the epidemiology of the COVID-19 outbreak in Wuhan. China. JAMA. 2020;323(19):1915-23. https://doi.org/10.1001/jama. 2020.6130.

91. Tang X, Du R, Wang R, Cao T, Guan L, Yang C, et al. Comparison of hospitalized patients with acute respiratory distress syndrome caused by covid-19 and H1N1. CHEST. 2020;158(1):195-205. https://doi.org/10.1016/j. chest.2020.03.032

92. Wang D, Hu B, Hu C, Zhu F, Liu X, Zhang J, et al. Clinical characteristics of 138 hospitalized patients with 2019 novel coronavirus-infected pneumonia in Wuhan. China. JAMA. 2020;323(11):1061-9.

93. Wu C, Chen X, Cai Y, Zhou X, Xu S, Huang H, et al. Risk factors associated with acute respiratory distress syndrome and death in patients with coronavirus disease 2019 pneumonia in Wuhan. China. JAMA Intern Med. 2020;180(7):934-43. https://doi.org/10.1001/jamainternmed.2020.0994.

94. Wu J, Liu J, Zhao X, Liu C, Wang W, Wang D, et al. Clinical characteristics of imported cases of coronavirus disease 2019 (COVID-19) in Jiangsu Province: a multicenter descriptive study. Clin Infect Dis. 2020;71(15):706-12. https:// doi.org/10.1093/cid/ciaa199.

95. Xu X-W, Wu X-X, Jiang X-G, Xu K-J, Ying L-J, Ma C-L, et al. Clinical findings in a group of patients infected with the 2019 novel coronavirus (SARS-Cov-2) outside of Wuhan, China: retrospective case series. BMJ. 2020;368 https:// doi.org/10.1136/bmj.m606

96. Yang $X, Y u$ Y, Xu J, Shu H, Liu H, Wu Y, et al. Clinical course and outcomes of critically ill patients with SARS-CoV-2 pneumonia in Wuhan, China: a single-centered, retrospective, observational study. Lancet Respir Med. 2020; 8:475-8. https://doi.org/10.1016/S2213-2600(20)30079-5.

97. Zeng L, Li J, Liao M, Hua R, Huang P, Zhang M, Zhang Y, Shi Q, Xia Z, Ning X, Liu D, Mo J, Zhou Z, Zigang Li YF, Liao Y, Yuan J, Wang L, He Q, Liu L, Qiao K. Risk assessment of progression to severe conditions for patients 
with COVID-19 pneumonia: a single-center retrospective study. medRxiv. 2020. https://doi.org/10.1101/2020.03.25.20043166

98. Zhang Y, Cui Y, Shen M, Zhang J, Liu B, Dai M, Chen L, Han D, Fan Y, Zeng Y, Li W, Lin F, Li S, Chen X, Pan P. Comorbid Diabetes Mellitus was Associated with Poorer Prognosis in Patients with COVID-19: A Retrospective Cohort Study. medRxiv. 2020; https://doi.org/10.1101/2020.03. 24.20042358.

99. Zhao W, Yu S, Zha X, Wang N, Pang Q, Li T, Li A. Clinical characteristics and durations of hospitalized patients with COVID-19 in Beijing: a retrospective cohort study. MedRxiv. 2020. https://doi.org/10.1101/2020.03.13.20035436.

100. Zhou F, Yu T, Du R, Fan G, Liu Y, Liu Z, et al. Clinical course and risk factors for mortality of adult inpatients with COVID-19 in Wuhan, China: a retrospective cohort study. Lancet. 2020;395:1054-62 https://doi.org/10. 1016/S0140-6736(20)30566-3.

101. Chen C-Y, Lee C-H, Liu C-Y, Wang J-H, Wang L-M, Perng R-P. Clinical features and outcomes of severe acute respiratory syndrome and predictive factors for acute respiratory distress syndrome. J Chin Med Assoc. 2005; 68(1):4-10.

102. Li B, Yang J, Zhao F, Zhi L, Wang X, Liu L, et al. Prevalence and impact of cardiovascular metabolic diseases on COVID-19 in China. Clin Res Cardiol. 2020:1-8.

\section{Publisher's Note}

Springer Nature remains neutral with regard to jurisdictional claims in published maps and institutional affiliations.

Ready to submit your research? Choose BMC and benefit from:

- fast, convenient online submission

- thorough peer review by experienced researchers in your field

- rapid publication on acceptance

- support for research data, including large and complex data types

- gold Open Access which fosters wider collaboration and increased citations

- maximum visibility for your research: over $100 \mathrm{M}$ website views per year

At $\mathrm{BMC}$, research is always in progress.

Learn more biomedcentral.com/submissions 